\title{
TOWARDS COMPLETE PROPERTY-LEVEL FLOOD PROTECTION OF DOMESTIC BUILDINGS IN THE UK
}

\author{
DAVID W. BEDDOES, COLIN A. BOOTH \& JESSICA E. LAMOND \\ $\mathrm{ABE} / \mathrm{CABER}$, University of the West of England, UK
}

\begin{abstract}
Property flood resilience (PFR) is an important aspect within an integrated approach to flood risk reduction. In the UK this has resulted in a plethora of products and recommended measures to minimise the ingress of water to the millions of properties at risk that are of traditional domestic masonry construction and limit property damage. The study considers the need for innovation to improve the take up of measures in the UK and demonstrates an innovative suite of measures that can be implemented to minimise and manage floodwater ingress of domestic buildings at various floodwater depths. The measures are shown to have advantages that potentially increase the number of properties at risk that can adopt such systems of risk reduction.
\end{abstract}

Keywords: innovation, product design, flooding, homeowners.

\section{INTRODUCTION}

Flooding is a significant and growing risk in the UK due to changes in weather patterns and increasing urban development and a priority for further action [1]. Furthermore, a substantial part of our supporting energy, water and communications infrastructure is in flood risk areas and in the future the flood risk in England will increase. DEFRA [3] states that part of its 2009-2015 strategy for managing flood risk is "Protective measures at individual properties to keep water from entering them and to reduce damage if water does enter". These protective measures are now commonly termed property flood resilience measures (PFR) and widespread support for their uptake in the UK has been reinforced in the recent Property Flood Resilience Action Plan [3].

Despite the severe impacts experienced by those that suffer flooding inside their homes [4], the uptake of PFR in the UK remains relatively low [5]. Research has identified three necessary steps for a homeowner to want to implement flood protection measures: awareness of risk, insight that the risk warrants action and owning the problem [5]. Furthermore, there is a need for knowledge and the resources to implement an effective solution, and belief in the measures available. Research shows that even when a homeowner is willing to act there is a very low awareness of the available types of flood protection [6], [7]. This is compounded by a lack of understanding and belief in the effectiveness of measures that affects property owners but also their advisors [8]. Emotional barriers to uptake include the reluctance to change the appearance of the home and the refusal to accept the possibility of flooding, particularly inside the home, as a cognitive coping strategy [7].

Best practice in PFR delivery has largely been driven by government research and industry (product providers) selling resistant measures. However, the recent BSI85500 [9] based on earlier research for the CLG recognises a need to accept some water entry for a variety of situations including a maximum height to which it is recommended to attempt to exclude water. Indeed, recent research for DEFRA challenged the dichotomy and called for a more holistic approach around managing water entry [8]. It follows that innovation in flood resilience technology that can bring increased confidence while 
recognising and managing the possibility of water ingress can help to build long term belief in PFR.

\section{INNOVATIONS IN PROPERTY FLOOD RESILIENCE}

To meet these needs this study aims to demonstrate a suite of measures that can be implemented to minimise and manage floodwater ingress into buildings of traditional domestic construction type for various floodwater depths. The suite of measures can be shown to address shortcomings with many existing barrier technology systems.

Minimising the amount of floodwater entering domestic buildings can be achieved through a suite of external property protection measures. There is a wealth of flood resistant products available for installation by skilled tradespersons or by homeowners themselves [10]. To maximise the resistance of a building to water ingress schemes will typically involve one of more aperture guards. Furthermore, some treatment of the brickwork may be necessary, particularly for flooding of longer duration. Backflow protection is also commonly installed. However, there are potential issues with both aperture guards and treatment of brickwork in terms of reliability and cost. The sections below describe the issues and innovations designed to overcome the challenges for door guards, full height flood doors and brickwork protection.

Flood resistance measures prevent flood water entering the property and are the preferred option for the majority of homeowners [7]. However even a complete package of resistance measures cannot guarantee protection due to factors such as flood height, duration of flood event, unprotected adjoining properties and ground conditions [6]. In recognition of the need to accept water ingress the final section describes an innovative management system that is designed to control water levels and minimise damage [2], [9].

\subsection{Door guards}

In general there are two types of external doorway that can be protected by door aperture guards. Firstly, a doorway with a concrete sill or low profile threshold (as used for disabled access) and, secondly, a modern UPVC doorset with bottom frame member and UPVC sill below. However, both types have inherent problems during flood events [11].

Considering the first type of doorway with concrete sill, the aperture guards currently available all suffer with the problem of trying to maintain sufficient downward pressure on the bottom edge seal in order to prevent water seepage into the property. Fitting a typical aperture door guard requires the homeowner to maintain downward pressure on the top of the guard, whilst simultaneously aligning multiple bolt holes in the guard with the threaded inserts set in the door frame, and then inserting and tightening bolts. This procedure can be challenging for homeowners, particularly as it is often carried out under stress, in poor weather conditions and perhaps after dark. In order to overcome this problem a new design was disclosed under patent application [12].

Fig. 1(a) is a line drawing to show the new guard fitted to the outside of a door frame. The two locating blocks $\mathrm{F}$ are temporarily fixed to the door frame G. The aperture guard A is then placed on the concrete sill $\mathrm{K}$ and pushed downwards so that the top edge $\mathrm{T}$ sits under the locating blocks $\mathrm{F}$ to compress the bottom seal $\mathrm{D}$. Aligning the sides $\mathrm{B}$ of the guard with the edges of the locating blocks $\mathrm{J}$ also aligns the boltholes $\mathrm{E}$ so bolts are easily inserted to compress edge seal C.

The second type of doorway is often fitted with guards that seal onto the door frame and bottom frame member but then seepage can occur between the frame and brickwork, most 


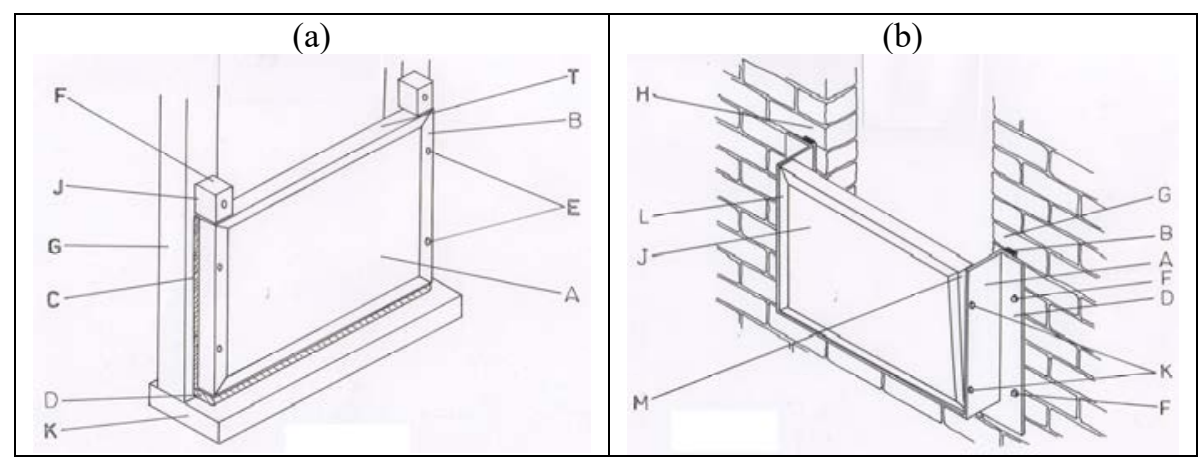

Figure 1: (a) Aperture guard for concrete sill; and (b) Adjustable aperture door guard for up to $2.8 \mathrm{~m}$ width.

particularly on the underside of the plastic sill, or water enters via sill weep holes that serve to drain the door of condensation or water ingress through glazing seals.

A new design [13] features a design that has structural fixings $F$ onto the external wall at the sides of the opening $\mathrm{H}, \mathrm{G}$ and below the sill. Two part construction allows adjustment to address any misaligned brickwork and the aluminium guard spans the brickwork opening to actually strengthen the area of structural weakness so that openings up to $2.8 \mathrm{~m}$ wide can be protected. Chemical anchor bolts are used to fix the guard in place and these are not discernible when the guard is removed.

Fig. 1(b) shows the two parts of the aluminium guard J and D, which are assembled onsite, using fixings $\mathrm{K}$, to allow for misaligned brickwork. To facilitate fixing the bottom edge of the frame rests on the ground whilst bolts are inserted through holes $\mathrm{F}$ to compress the seal B. Table 1 identifies the advantages and disadvantages of this measure.

\subsection{Flood doors}

Door aperture guards are purposely designed to be only $600 \mathrm{~mm}$ high so when floodwater exceeds this height it overtops and does not compromise the structural integrity of the building they are protecting. In contrast, flood doors can hold back flood water to heights in excess of the $600 \mathrm{~mm}$ safe structural limit for brick walls. Furthermore, there is a safety concern of a homeowner opening a flood door with water pressure acting on the outside [14], [15]. For instance, at $750 \mathrm{~mm}$ flood depth there is almost half a tonne of force exerted on every metre of wall.

A cost effective solution to overcoming these problems was disclosed [16] using a conventional UPVC door that opened outwards and featured a door frame with external flange that formed a waterproof seal against the external brickwork. The door featured a double rebated edge with rubber seals so that increased levels of floodwater pressing on the door increased both pressure on the flange and seals resulting in a more watertight door. Furthermore, the door featured a hinged buoyant letter flap set at $600 \mathrm{~mm}$ above floor level to let floodwater in and prevent structural damage. A clapper valve set into the lower transom would let water out as the flood receded. Deployment by the homeowner is not necessary and the automatic flood water ingress would prompt occupiers to leave the property before their rescue became too dangerous. Table 1 identifies the advantages and disadvantages of this measure. 
Table 1: Advantages and disadvantages of the three types of door measures. (Source: [36], [37].)

\begin{tabular}{|c|c|}
\hline \multicolumn{2}{|l|}{ Aperture guard for low profile sill } \\
\hline Advantages & Disadvantages \\
\hline Used for disabled access & Must be deployed before flood \\
\hline Easy and quick to fit as held by blocks & No seal between door frame and bricks \\
\hline Lightweight & Must be kept safe with fittings by door \\
\hline Low cost $\sim £ 200-£ 300$ & $\begin{array}{l}\text { Suitable for standard doors sizes only } \\
\text { Can be stolen whilst deployed }\end{array}$ \\
\hline \multicolumn{2}{|c|}{ Two-part aperture guard for openings } \\
\hline Advantages & Disadvantages \\
\hline Used for any type of opening in walls & Must be deployed before flood \\
\hline Easy and quick to fit rests on path & Heavy item for wide openings \\
\hline Fits uneven or twisted openings & Must be kept safe with fittings by door \\
\hline Spans up to $2.8 \mathrm{~m}$ openings & Can be stolen whilst deployed \\
\hline Can be fitted across sliding doors & Prevents doors opening outwards \\
\hline Low cost $\sim £ 300-£ 500$ & \\
\hline \multicolumn{2}{|l|}{ Flood door } \\
\hline Advantages & Disadvantages \\
\hline Passive - no deployment needed & Standard door sizes only \\
\hline Safe as cannot be opened by mistake & No seal between door frame and bricks \\
\hline No complex locking mechanism & Damage to seals due everyday usage \\
\hline Water ingress through flap at $600 \mathrm{~mm}$ & Misalignment due to everyday usage \\
\hline Water pressure compresses door seals & Needs retaining strap for high winds \\
\hline Cannot be stolen & Restricts outside path access. \\
\hline Looks the same as other UPVC doors & Expensive $\sim £ 800-£ 900$ \\
\hline
\end{tabular}

\subsection{Treatment of masonry}

Despite the installation of these measures halting floodwater ingress through routes of large openings, such as doorways, minimal attention has focussed on reducing ingress through the brickwork of external walls. A pilot study [17] has demonstrated a means of minimising floodwater ingress to manageable levels, which lessens impact and damage to the fabric of the internal building. Whereby, prior to treatment an existing masonry wall was tested using three sets of apparatus to give three sets of readings for water ingress. Following extensive consultation with several leading chemical manufacturers a silane-based product was chosen for testing. As a result of the manufacturers recommendations the treatment procedure involved repointing using a silane-based admixture together with spraying the surface of the repointed masonry. After curing for 14-days the masonry was retested with the equipment in exactly the same positions as before. Fig. 2(b) shows the difference in mean floodwater ingress rates (litres $/ \mathrm{hr} / \mathrm{m}^{2}$ ) at various floodwater heights. In general terms the treatment reduced the ingress rates by two thirds, mean untreated ingress rate was 234.99 litres $/ \mathrm{hr} / \mathrm{m}^{2}$ and mean treated rate 81.90 litres $/ \mathrm{hr} / \mathrm{m}^{2}$.

The experimental work [18] showed that it was not possible for large amounts of water to pass directly through individual bricks and mortar. The research showed that the water 


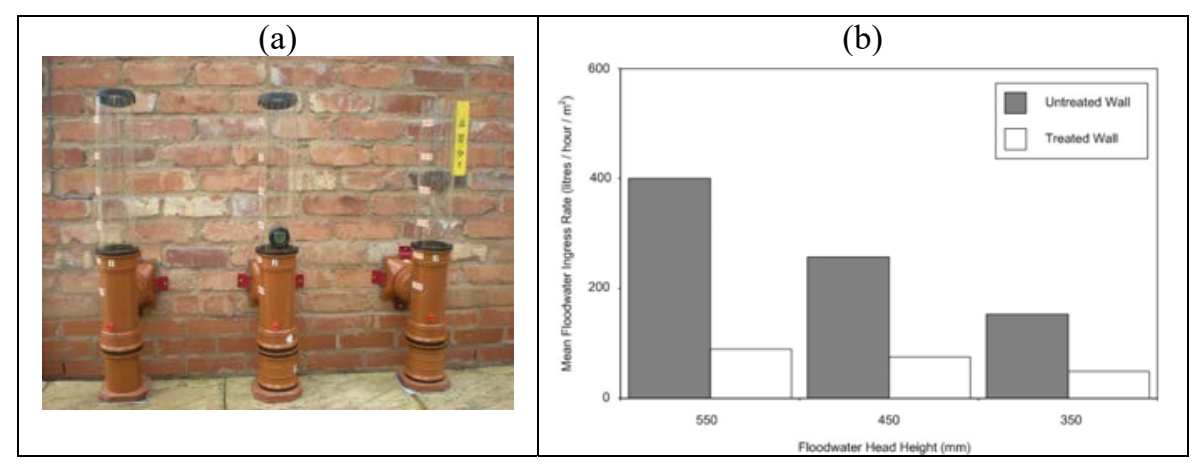

Figure 2: (a) Three sets of new replicate field test apparatus; and (b) Mean floodwater ingress rates at various flood water head heights.

penetration through a completed wall is not affected by the permeability of constituents but occurs as a direct result of conditions at the interface between brick and mortar, which is dependent on a quality of the brick known as initial rate of absorption (IRA), together with mortar mix and the skill of the mason when laying. The permeability of a wall is due to the "extent of bond" and is directly affected by compatibility of materials and also any flaw in construction, such as a repositioned brick.

Water permeability of masonry walls is dependent on cement hydration at the interface between masonry unit (brick) and mortar at the time that the masonry unit is laid onto the mortar bed. The interface join is the intimate contact area between the masonry unit and the mortar and it is important to realize that it is not the mortar joint itself. The interface join and resultant "extent of bond" that resist water penetration occur immediately after the brick is laid onto the mortar bed. The majority of masonry walls must, therefore, be regarded as prone to large rates of water ingress due to incompatibility and/or defects introduced during the laying of the bricks [15], [19], [20].

In order to be absolutely certain that the resistance of a masonry wall is raised to an acceptable level the "extent of bond" at the interface between brick and mortar must be addressed in areas where standing floodwater will come to bear against the masonry wall. The interface could be sealed by the application of a complete external rendering or waterproof coating; however renders have many disadvantages [18], [21]-[23].

The experimental work supported the use of an impregnation for improving the water resistance of masonry and further consultations with the manufacturer led onto further experimental work to investigate the method of application and effectiveness of silanebased products.

\subsection{Managing floodwater entry}

Accepting that some floodwater will penetrate through the external envelop of buildings, a suite of internal property protection measures can be installed to lessen the damage to the internal fabric of the building. There is a wealth of measures available for installation by skilled tradespersons or by homeowners themselves [10], [24].

Whilst the installation of these measures means floodwater damage to the internal fabric can be minimised, few of the aim to control flows. However, an increasing use of membranes is being proposed and implemented by the property protection industry as a 
means of speeding recovery [24]. Among these are methods proposed by [25], [26] involving perimeter floor drains and a dado wallboard as a potentially unique way to managing floodwater levels inside the building while limiting the risk of structural damage. The following sections portray these approaches of managing floodwater once it has entered the building.

As opposed to tanking which tries to resist water, drained protection using a combination of membranes and perimeter floor drains (PFD) to manage water can be installed as part of new-build or retro-fitted to existing property and within the construction industry it is known as Type-C waterproofing. Problems have occurred in the past with cavity membranes being incorrectly used as merely a damp proof membrane being devoid of drainage and also blockages occurring within some Type-C installations. Revised British Standards [27] now recommend all Type-C installations to be accessible and maintainable which has lead onto the development of new patented products which have been successful within the waterproofing industry [27]. To illustrate the installation of flood resilient TypeC protection we refer to Fig. 3(a) a cross-sectional line drawing of an external cavity wall. The outer masonry (1) is impregnated with a silane-based product to seal the interface joins (18). The reduced quantity of flood water that passes through the outer masonry wall will enter the wall cavity (2) and sit above cavity fill (19). Conventional weepholes above cavity fill have been sealed (plastic check valves are available) and drilled holes (5) allow any water in the cavity to remain below the insulation (17) and pass through the inner skin (3) and into the PFD (4).

The ventilated PFD (mechanical or passive) (4) is positioned around the perimeter of the solid floor (14). In installations where the rate of flood water ingress into the cavity is very high e.g. due to prolonged flood duration and/or very porous external masonry an $8 \mathrm{~mm}$ cavity membrane (20) must also be fixed (11) against the inside face of the internal wall (3) under the plaster finish (9) to collect any water ingress and transfer it to the PFD (4). A further cavity membrane (13) with floor finish over (12) and skirting board (10) is laid above the solid floor to collect floodwater ingress rising through the hardcore (16) and then through damp proof membrane (15) defects and joins in the solid floor (14).

Floor membranes (13) can be $8 \mathrm{~mm}$ or $20 \mathrm{~mm}$ dependent on floor condition, size and level and must be sealed (23) to the PFD (4). Floor finish over membranes can be screed or treated chipboard with laminate above. The PFD (4) collects water ingress from both walls

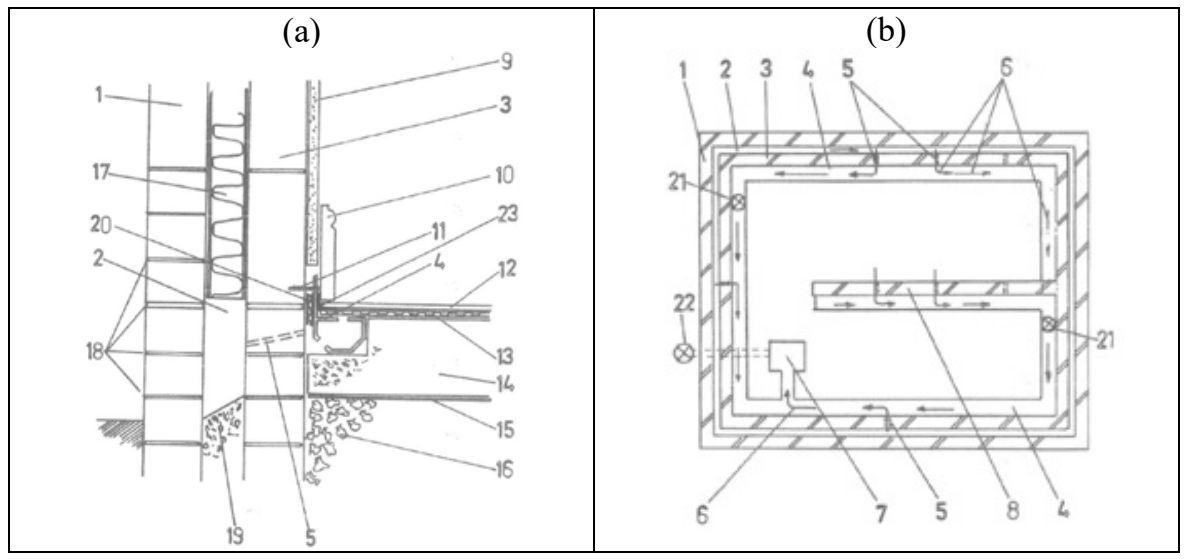

Figure 3: (a) Silane treated external wall with PFD; and (b) Plan view of PFD installation. 
and floors transferring it to a sump for removal from the property. Fig. 3(b) is a plan view to show the installation to a building with silane treated outer masonry (1), cavity (2) and inner masonry skin (3). Drilled holes (5) pass flood water to PFD (4). Arrows (6) show water passing along PFD (4) and into sump (7). Internal walls have a PFD on one side only and are cross-drilled to collect water from both sides (8). The floor slab is covered by a cavity membrane under which any water will move to the PFD and then to the sump (7). The sump features both mains and battery powered pumps to expel water through external outlet (22). The PFD (4) is ventilated by internal stacks (21). In order to solve the historical defects and satisfy the recommendations of BS8102: 2009 the required accessibility and maintenance are satisfied by two novel patented products: patent [28] "Drain deflector" granted 30/07/2014 and [29] "Perimeter floor drain T piece" granted 12/11/2014. Fig. 4(a) shows the "drain deflector" which is a pivotally connected elbow bend that clips into place in corners to maintain both axial and invert alignment. This being an important feature because a floor slab is level and accurate alignment is necessary to ensure a flow of water along the PFD (S). The top sections of the PFD (P) use pivotal connections (Q) to the deflector plate $(\mathrm{R})$ leaving a gap $(\mathrm{W})$ for adjustment during installation.

The internal deflector plate (R) facilitates water flow and helps with flushing out around the PFD during maintenance and also allows inspection cameras to pass around the drain if problems arise. Fig. 4(b) is the T piece which clips into place at junctions in the PFD (S) such as the link drain to the sump. The PFD top sections (U), (V) use a pivotal connector (Q) for adjustment during installation. An internal deflector adds strength to the fitting and more importantly allows a water supply or inspection camera to be inserted via the sump chamber and passed along the PFD for flushing out or periodic inspection. The combination of $\mathrm{T}$ piece deflector and corners with deflectors allows for inspection and flushing out of complete PFD systems meeting recommendations of [27].

An "access point" allowing entry to a PFD at any point around the perimeter of a room was disclosed under patent application [30] and this could also be retro-fitted to any type of wall or floor finish. The Type-C resilient protection can be installed when flood heights are below $600 \mathrm{~mm}$ and the internal appearance will be the same as any other home.

However, when flood water can rise to more than $600 \mathrm{~mm}$ above floor level then structural damage can result if the water is not let into the building [31]. Therefore, to again preserve the aesthetics of the property in deep flood events a "dado wallboard" was

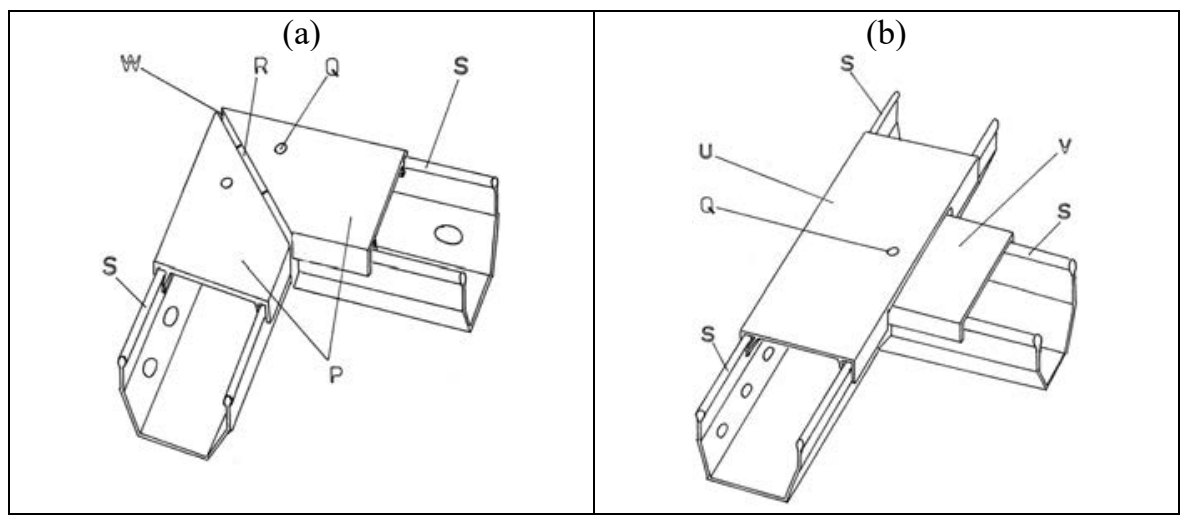

Figure 4: (a) Pivotally connected elbow with deflector; and (b) Pivotally connected T piece with deflector. 


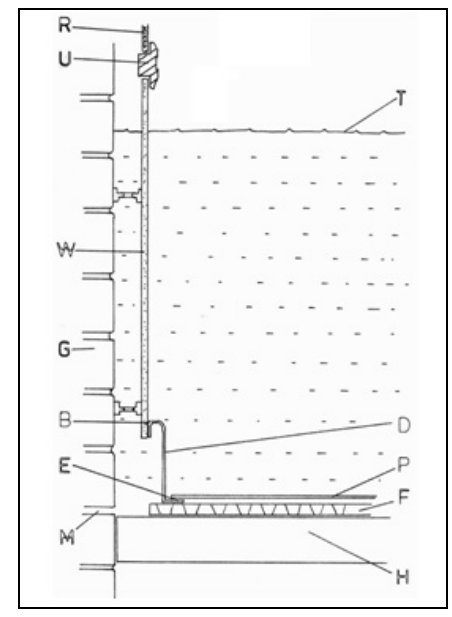

Figure 5: Dado wallboard fitted to building and water allowed to enter.

building where flood water can cause structural damage and so it has been let into the building. The floodwater level inside the building is shown as (T). The inner skin of the masonry wall $(\mathrm{G})$ has a hole at $(\mathrm{M})$ to allow water to pass from the cavity.

Conventional plasterboard $(R)$ is fixed to the internal wall $(G)$. The waterproof dado wallboard (W) made from magnesium-oxide or similar is mechanically fixed to wall (G) and the dado rail $(\mathrm{U})$ is removable. The aperture at the bottom of the dado wallboard can be uncovered by removing the skirting board (D) which is fixed to the dado wallboard at (B) and the floor at $(\mathrm{E})$. A solid floor $(\mathrm{H})$ supports the floor membrane $(\mathrm{F})$ with floor covering (P) laid over. The skirting board (D) can be a hollow type as patent [33] Skirting granted $2 / 9 / 2009$ or the hinged type as patent [4] "flexible skirting" granted 20/10/2009. After a flood event removal of the dado rail (U) and skirting (D) allows access to the cavity behind the dado wallboard to first sanitize the area and secondly introduce forced air circulation to dry out the wall structure so the property can be re-occupied at the earliest date. The dado wallboard system is cost effective, looks no different from other homes and reduces postflood reinstatement costs.

\section{DISCUSSION}

The protection systems described above address some of the concerns expressed about PFR that may be limiting uptake. Using flood doors and masonry treatment allied with resilience using Type-C waterproofing membranes retains the look of the normal home. The new Type-C installation can be regularly inspected, it can be tested in-situ, it is maintainable and it manages water as opposed to the old tanking system which tried to resist water ingress. As shown in a modified table from [9] these measures can also be modified and implemented for a range of typical UK flood depths and even when flood water must be allowed into the property the dado wallboard offers a solution that facilitates early rehabilitation (Table 2). The above suite of measures would arguably be aesthetically acceptable and could be promoted for new build and retrofit within the private sector.

Although these innovations do not reduce the cost of installing PFR, by addressing the potential for resistant systems to be exceeded or fail they have the benefit of increasing credibility in preventing damage. This damage can be up to $£ 45,000$ in a typical home [38], 
[39]. Improved credibility may allow insurers to recognise the installation of measures through reduced premiums and excesses. In accordance with the recommendations of [9] we can, therefore, specify property level flood protection products that may be more acceptable to the homeowner. With regard to costs it is most effective to install resilience measures during reinstatement after a flood event [40]. Work using data from loss adjusters has shown that the percentage increased cost for resilient over traditional reinstatement is on average 34 per cent. Importantly, for properties with a flood frequency of 25 years or less full recovery of the additional cost is realised after only one further flood event [40]. Furthermore, the data analysed included costs for the installation of resilient renders, UPVC claddings, hardwood stairs, removable doors and waterproof kitchen units, all of which are not required for a membrane water management option and so their costs can be saved and offset against the membranes and pumps.

The potential for effectiveness for the new products has been demonstrated through sales to construction companies involved in waterproofing and flood protection. Many of the products have been installed in basements where their functionality requires a continuous performance far more onerous that on an occasional flood application. However, it is apparent that those who are skilled in the business of waterproofing are not always eager to take on flood installations for several reasons. Chief among these is the lack of evidence, standards and guidance that can justify the extra expense of holistic systems that result in a lack of demand and, therefore, a lack of economies of scale [8]. Recent government grant schemes implying that flood resilience can be achieved for $£ 5,000$ have not helped the perception that "flood protection" is simply a matter of fitting two door guards and an airbrick. Furthermore, the advent of Flood Re may disincentivise home owners and insurers from taking a long-term view of the realistic costs and benefits of PFR [35].

\section{CONCLUSIONS}

It is generally accepted that PFR will often require a combination of resistance and recoverable measures. The measures described here represent accessible and maintainable systems together with a combination of resistance products that can offer maximum protection for the homeowner. This includes measures, which when floodwater exceeds

Table 1: Selection of strategies from [9] with example products.

\begin{tabular}{|l|l|l|}
\hline $\begin{array}{l}\text { Floodwater } \\
\text { depth }\end{array}$ & Strategy & Appropriate measures \\
\hline$<300 \mathrm{~mm}$ & $\begin{array}{l}\text { Resistance (groundwater } \\
\text { and long duration could } \\
\text { need resilience as well) }\end{array}$ & $\begin{array}{l}\text { Flood door, flood aperture guard. } \\
\text { Masonry treatment with silanes. } \\
\text { Skirting or Flexible skirting. } \\
\text { (added resilience where necessary } \\
\text { with Type-C protection to } \\
\text { BS8102: 2009 possibly without } \\
8 \mathrm{~mm} \text { wall membranes. }\end{array}$ \\
& & $\begin{array}{l}\text { As }<300 \mathrm{~mm} \text { above plus resilience } \\
\text { Type-C protection to include } \\
8 \mathrm{~mm} \text { wall membranes. }\end{array}$ \\
\hline $300 \mathrm{~mm}$ to & Resistance and resilience & As $<300 \mathrm{~mm}$ above plus dado \\
$600 \mathrm{~mm}$ & & wallboard. \\
\hline$>600 \mathrm{~mm}$ & $\begin{array}{l}\text { Resilience (plus resistance } \\
\text { for lesser events) }\end{array}$ & \\
\hline
\end{tabular}


$600 \mathrm{~mm}$ and floodwater enters the building, can facilitate rapid drying and reoccupation. One of the best PFR solutions is initial resistance using the safe passive flood doors together with masonry impregnation to reduce water ingress. This can then be combined with a membrane water management system that can be installed and tested in-situ. Financial cost of these measures accord with other resilient reinstatements carried out after a flood event but the massive savings in human cost considering the great stress caused by relocation and reinstatement work to homes after a flood makes this a preferable option. Furthermore, this approach solves the important barriers of aesthetics and contamination issues that can deter homeowners from acting. Hence, the measures described here can address known barriers to uptake and have the potential to improve the resilience of the UK domestic building stock if widely adopted.

\section{REFERENCES}

[1] HM Government, UK Climate Change Risk Assessment, HM Government: London, 2017.

[2] EA, Flooding in England. A National Assessment of Flood Risk, Environment Agency: Bristol, 2009.

[3] Bonfield, P., The Property Flood Resilience Action Plan, DEFRA: London, 2016.

[4] Tapsell, S.M., Tunstall, S.M. \& Wilson, T., Banbury and Kidlington Four Years after the Flood: An Examination of the Long-Term Health Effects of Flooding, Report to the Environment Agency, Thames Region, Flood Hazard Research Centre: Middlesex University, Enfield, 2003.

[5] Lamond, J.E. \& Proverbs, D.G., Resilience to flooding: lessons from international comparison. Urban Design and Planning, 162, pp. 63-70, 2009.

[6] Department for Environment, Food and Rural Affairs, Consultation on Policy Options for Promoting Property-Level Flood Protection and Resilience, DEFRA: London, 2008.

[7] Harries, T., Householder Responses to Flood Risk: The Consequences of the Search for Ontological Security. Unpublished PhD thesis, Middlesex University, London, 2008.

[8] Lamond, J. et al., Supporting the Uptake of Low Cost Resilience: Final Report (fd2682), DEFRA: London, 2017.

[9] British Standards Institution, BS85500: 2015 Flood Resistant and Resilient Construction: Guide to Improving the Flood Performance of Buildings, London, 2015.

[10] Dhonau, M. \& Rose, C.A., Business Guide to Flood Resilience, 2016. Online. www.knowyourfloodrisk.co.uk.

[11] Beddoes, D.W. \& Booth, C.A., Novel solutions to a traditional method of propertylevel flood protection: Technical insights of innovative door aperture guards. Sustainable Cities IX, WIT Press: Southampton, pp. 1255-1266, 2014.

[12] Patent GB1401368.4.

[13] Patent GB1404806.0.

[14] Kelman, I., Physical Flood Vulnerability of Residential Properties in Coastal, Eastern England. PhD thesis, University of Cambridge, UK, 2003.

[15] Kelman, I. \& Spence, R., An overview of flood actions on buildings. Engineering Geology, 73, pp. 297-309, 2004.

[16] Patent GB1315021.4. 
[17] Beddoes, D.W. \& Booth, C.A., Reducing floodwater ingress rates through an exterior masonry wall of a domestic building: A pilot investigation. Structural Survey, 33, pp. $1-15,2015$.

[18] DCLG, Improving the Flood Resilience of Buildings through Improved Materials, Methods and Details, RIBA Publishing: London, 2006.

[19] Brick Industry Association, Technical Notes on Brick Construction 7A: Water Penetration Resistance-Materials, Brick Industry Association: Reston, Virginia, pp. $1-10,2005$.

[20] Groot, C.J.W.P. \& Gunneweg, J.T.M., The influence of materials characteristics and workmanship on rain penetration in historic fired clay brick masonry. Masonry Design and Detailing, ed. C. Beall, 5th ed., McGraw Hill: New York, pp. 141-153, 2004.

[21] Crook, R. \& Day, R., Rendering: Defects and Remedial Measures. The Concrete Society, Concrete Advice No 24, The Concrete Society: Camberley, 2005.

[22] Monks, B., Rendering: A Practical Handbook. Concrete Society Good Concrete Guide No 3, The Concrete Society: Crowthorne, 2000.

[23] BRE, Defect Action Sheet (Design) External Walls: Rendering - Resisting Rain Penetration, BRE: Watford, 1983.

[24] Lamond, J., Rose, C., Joseph, R. \& Proverbs, D., Supporting the Uptake of Low Cost Resilience: Summary of Technical Findings (fd2682), DEFRA: London, 2016.

[25] Beddoes, D.W. \& Booth, C.A., Factors for the design of novel property-level flood resilient products: The dado wallboard. Flood Recovery Innovation and Response III, WIT Press: Southampton, pp. 205-219, 2012.

[26] Beddoes, D.W. \& Booth, C.A. Waterproofing basement apartments: technical insights of a new flood protection solution. Flood Recovery Innovation and Response IV, WIT Press: Southampton, pp. 151-162, 2014.

[27] British Standards Institution, BS8102: 2009 Code of Practise for Protection of Below Ground Structures Against Water from the Ground, London, 2009.

[28] Patent GB2485426.

[29] Patent GB2485429.

[30] Patent GB1102661.4.

[31] USACE, Flood Proofing Performance - Successes and Failures, US Army Corp of Engineers: USA, 1998.

[32] Patent GB1021254.6.

[33] Patent GB2449777.

[34] Patent. GB2452423.

[35] Surminski, S. \& Eldridge, J., Flood Insurance in England: An Assessment of the Current and Newly Proposed Insurance Scheme in the Context of Rising Flood Risk. Working paper. Grantham Research Institute on Climate Change and the Environment, Centre for Climate Change Economics and Policy: Leeds and London, 2014.

[36] Johnson, V.B., Laxtons SMM Building Price Book, Laxtons Publishing Limited: Milton Keynes, 2017.

[37] AECOM, Spon's Architects and Builders' Price Book, 142nd ed., CRC Press: Abingdon, 2017.

[38] Kazmierczak, A. \& Bichard, E., Investigating homeowners' interest in propertylevel flood protection. International Journal of Disaster Resilience in the Built Environment, 1, pp. 157-172, 2010. 
38 Urban Water Systems \& Floods II

[39] Association of British Insurers, Flood Resilient Homes. What Homeowners can do to Reduce Flood Damage, 2004. Online. www.westoxon.gov.uk/media/ 172419/Flood-resilient-homes-leaflet.pdf.

[40] Joseph, R., Proverbs, D.G., Lamond, J. \& Wassell, P., An analysis of the costs of resilient reinstatement of flood affected properties: A case study of the 2009 flood event in Cockermouth. Structural Survey, 29, pp. 279-293, 2011. 